\title{
The Effectiveness of Using Melodic Sentence Structure on Sentence Writing: A Mixed Methods Approach
}

\author{
Mahendran Maniam, Aladdin Assaiqeli, Shanti Ramanlingam Farah \\ Wahibbah Hilaluddin, Rebecca Mary Sartho
}

To Link this Article: http://dx.doi.org/10.6007/IJARBSS/v10-i11/8196

DOI:10.6007/IJARBSS/v10-i11/8196

Received: 12 September 2020, Revised: 14 October 2020, Accepted: 10 November 2020

Published Online: 26 November 2020

In-Text Citation: (Maniam, Assaiqeli, Hilaluddin, \& Sartho, 2020)

To Cite this Article: Maniam, M., Assaiqeli, A., Hilaluddin, S. R. F. W., \& Sartho, R. M. (2020). The Effectiveness of Using Melodic Sentence Structure on Sentence Writing: A Mixed Methods Approach. International Journal of Academic Research in Business and Social Sciences. 10(11), 1195-1207.

Copyright: (c) 2020 The Author(s)

Published by Human Resource Management Academic Research Society (www.hrmars.com) This article is published under the Creative Commons Attribution (CC BY 4.0) license. Anyone may reproduce, distribute, translate and create derivative works of this article (for both commercial and non-commercial purposes), subject to full attribution to the original publication and authors. The full terms of this license may be seen

at: http://creativecommons.org/licences/by/4.0/legalcode

Vol. 10, No. 11, 2020, Pg. 1195 - 1207

Full Terms \& Conditions of access and use can be found at http://hrmars.com/index.php/pages/detail/publication-ethics 


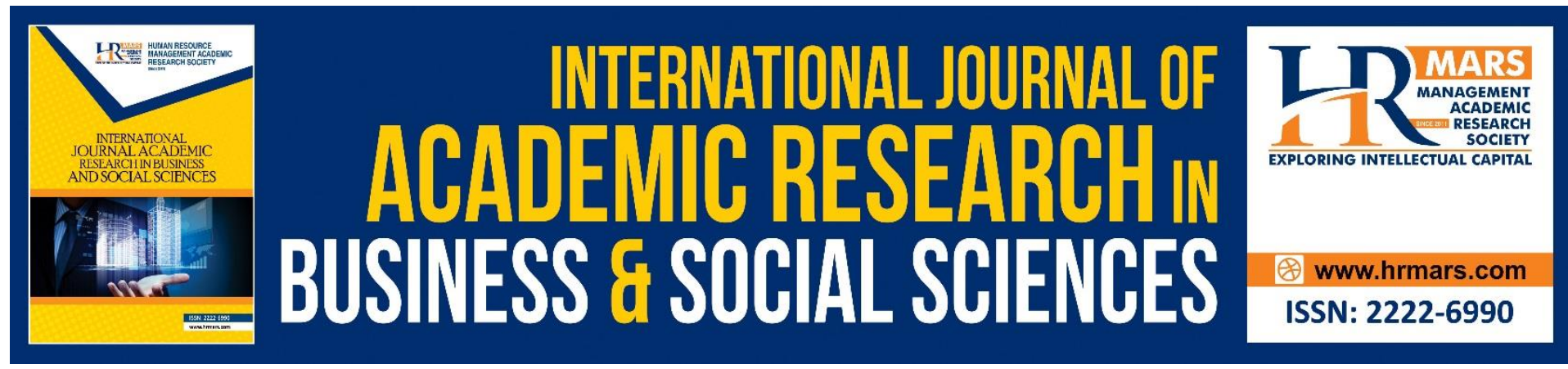

\title{
The Effectiveness of Using Melodic Sentence Structure on Sentence Writing: A Mixed Methods Approach
}

\author{
Mahendran Maniam, Aladdin Assaiqeli, Shanti Ramanlingam \\ Farah Wahibbah Hilaluddin, Rebecca Mary Sartho \\ English Language and Literature Department, Faculty of Languages and Communication, \\ Sultan Idris Education University (UPSI), Tanjong Malim, Perak, Malaysia.
}

\begin{abstract}
This study aims to find out the effectiveness of using melodic sentence structure on enhancing the pupils' ability to write sentences. The study adopted a mixed-method approach where two types of data collection tools were used - a pre-test and a post-test as well as an interview. The participants of this study were Year Five pupils from a rural area school at Southern Perak. There were altogether 20 pupils involved in this study who had problems in writing sentences with correct sentence structure. Based on the findings, the pre-test and post-test results showed that the mean score of post-test is significantly higher than the pretest. This increase in post-test indicated positive improvement in the pupil's performance level in sentence writing. The findings from the interview revealed that the pupils have positive perceptions about using the melodic sentence structure as a strategy to improve sentence writing. Five themes obtained from the interview summarized all the perceptions of pupils' in the effectiveness of using this type of sentence structure on improving sentence writing. The findings strongly concluded that melodic sentence structures or the help of using songs and music to write sentences can be an effective tool in aiding the pupils to master certain sentence structures.
\end{abstract}

Keywords: Effectiveness, Music, Melodic Sentence Structure, Songs, Sentences, Writing, Writing Skill

\section{Introduction}

Teaching of English aims at helping learners master four basic skills of language: listening, speaking, reading, and writing. Students will be exposed to all these skills in the early years of schooling as these skills are very important for language production. The writing skill is one of the hardest to teach and learn especially for young learners as it needs the acquisition of all the other skills. The Malaysian Primary Curriculum Standard known as Kurikulum Standard Sekolah Rendah (KSSR) has made a strong emphasis on writing skills. One of the objectives of KSSR focuses on writing skills. It is stated that the writing skill is very important to be taught in primary school and the pupils should be exposed to writing composition step-by-step. At the end of primary schooling, pupils are graded based on their Primary School Evaluation Test 
known as Ujian Pencapaian Sekolah Rendah (UPSR). The writing skill plays a major part in this test.

\section{Writing}

Klimnova (2014) states that writing has a unique role in language teaching as it requires the learning and understanding of three other language skills: listening, speaking and reading. Writing is a productive skill and it involves various elements. Sapkota (2012) states that writing comprises numerous components such as subject matter, purpose, interaction and sense of audience, language, conventions, thinking skills, organizational skills, value systems, and mechanics making writing a complex skill or communicative activity. These requirements help to convey the message easily and clearly. These same requirements, however, may discourage ESL students from engaging in writing.

The writing skill is considered a difficult skill, particularly in the context of English as a Second Language (ESL) where pupils face many challenges in writing. It is undeniable that the teaching and learning processes of this skill are contextually difficult. It remains, however, the responsibility of ESL teachers to guide and help the pupils to master writing skills, progressively. Supiani (2017) observes that writing skills should not be taught palely and teachers must think of ways to teach writing using different approaches.

Writing is an important tool especially, for communication that is transmitted through writing, particularly in educational and work contexts. In this case, students must develop effective writing skills in order to fulfill their educational and working needs. Teachers play an important role in guiding the students to improve their writing skills through instruction and a brief explanation on grammar rules as well as through providing them with plenty of writing opportunities and practices.

There are various approaches for the teaching of writing that teachers could adopt and adapt to suit the level of their students. When the students are able to do well in the writing activity, they can improve their understanding of any subject. Iftanti (2016) states that writing is not only a process of putting thoughts on a piece of paper but also helping develop more sensible explanations and clarify ideas. Writing, in a word, is an essential skill to acquire as it is frequently used in everyday life in a variety of contexts of languaging or interaction whether for messaging, texting, emailing, or engaging in any social media platform, etc.

\section{Melodic Sentence Structure}

The integration of music and songs into language teaching has always been an effective approach that creates a fun learning environment. Melodic sentence structure (MSS) includes the use of song and focuses more on 'singing the structure.' This method was initiated by C.C. James (2013) who emphasized the use of simple melodies as a strategy to teach sentence construction, which can relatively improve the pupils' memory to remember simple sentence structure. The focus of language teaching gradually changed from spoken and reading text to musically based teaching. The use of melody could provide more opportunities to practise the second language through engaging and entertaining songs.

The aim of incorporating MSS or the method of singing the structure into classroom language teaching is to help low proficiency pupils to write simple sentences with correct sentence structure. Singing the structure can be very useful for retention of the structure as well as activating their memory through the repetition in the song which may enhance pupil's language learning and acquisition. James (2013) created two writing formulas to develop basic sentence construction skills for weaker upper primary students. The first is TiTa Formula 
- a formula used to guide pupils to write sentences using the 'There is.../There are...' structure where 'Ti' stands for 'There is...' while 'Ta' stands for 'There are...'. The formula is "There + Be + How many? + Noun + Place."

However, this research only adopts and adapts the second formula, the S-V-W Formula as it is very much related to and useful for UPSR Writing paper. The S-V-W Formula is a formula used to help pupils to construct sentences in the Present Continuous Tense. ' $S$ ' stands for 'Subject', ' $V$ ' stands for 'Verb' and ' $W$ ' for 'Wh-questions.' The formula is "How many? + Subject + Be + Verb+ing + What / Where /Who" (see Table below?).

\begin{tabular}{lllll}
\hline How many? & Subject & Be & Verb+ing & What/ Where/ Who \\
\hline A & girl & is & eating & a sandwich. \\
\hline Several & people & are & watching & the football game. \\
\hline
\end{tabular}

Table 1: S-V-W Formula

This study amends the second formula by making the structure much simpler - a Subject + Past Tense + What/Where/Who (see Table 2 below). This is to help low proficiency pupils to write simple sentences which will be used in writing a narrative essay for Section $C$ of the Writing Paper. It is also to encourage them to write simple and "rich" sentences where each sentence provides enough information and details based on the series of pictures given.

\begin{tabular}{lll}
\hline Subject & Verb - Past Tense & What/ Where/ Who \\
\hline Aqilah & ate & a sandwich at the canteen. \\
\hline Chong & watched & the football game with \\
& Haikal at the stadium.
\end{tabular}

Table 2: The adapted S-V-W Formula

\section{Significance of the Study}

This paper aims to introduce, drill, aid in memorization, and stimulate pupils' interest to write and grammaticalize certain sentence structures in various contexts naturally and meaningfully, using simple melodies where pupils will be interested and motivated in learning writing with the help of the integration of music. The integration of simple melodies into sentence structure improves grammaticalization; emphasizes the students' understanding of the structure and guides them to utilize the structure to generate sentences that follow the same pattern or system. The main focus of this research is not merely introducing sentence structure to teach writing but rather integrating simple melodies into these sentence structures. Music is an effective method to be implemented in language teaching as it is naturally designed in a way that can quickly appeal to the learner and easily become internalized in the mind as songs work more efficiently for short- and long-term memory (Engh, 2013). This study focuses on providing the pupils with a framework that can help them generate sentences in a fun and entertaining way. The use of melodic sentence structure in the classroom will be very helpful to teaches who are teaching the English language in rural areas where the proficiency level of students is very low.

\section{Literature Review}

James (2013) created a pre-writing module with the two formulas of TiTa and S-V-W as a guide to enable low proficiency upper primary pupils to develop and acquire the basic skills of sentence construction. The study was conducted for Year 6 pupils for seven months. Apart 
from the formulas, the module also includes vocabulary, grammar items. It also provides exercises using past year UPSR questions, pictures along with grammar exercises from the textbook. The module was given to pupils and the implementation was conducted by singing the structure every time during writing lessons to revise and in the process grammaticalize the sentence structure. The findings of the study show that the module has successfully managed to enhance the sentence writing skill and relatively improve the pupils' sentence writing ability. Despite being a tool for teaching writing, the song was also enjoyable, fun and encouraged the pupils to learn writing.

In another study, Atmojo (2015) proposes a method of integrating "There is an Animal" song to teach young learners vocabularies and basic sentence structures. He believed that songs could be an effective pedagogical tool since the use of songs gives a lot of advantages and benefits to young learners. Songs are regarded as a unit of text memory that can effectively support language acquisition in a fun and entertaining way. Besides, the song also improves acquisition of the language structure, specifically sentence structure. The song was implemented through three stages of activities: preparation, core activity, and follow up. These activities can be identified, analyzed, adapted and expanded as classroom tasks for learners. The study concludes that when the utilization of songs is well-planned and structured in conducting engaging tasks, then these stages can enhance the learner's language skills pedagogically. Learners' will be having well-developed language skills and linguistic knowledge in a relaxed stimulating environment.

One of the issues faced by teachers is maintaining learners' interest throughout the lessons. Several studies have found that songs can provide a more relaxing atmosphere for stimulating learning and enhancing motivation in learning. According to Millington (2011), songs could be used in various modified ways to fit the teacher's expectations. He also claimed that songs are regarded as a valuable pedagogical tool that helps learners to develop their vocabulary and sentence structure. In addition, by introducing songs into the classroom, it can stimulate elements in language teaching and promote higher retention rates of repetitive language in melody. The integration of music is fun and helpful for retention and the acquisition of the sentence structure. The author has proved that the use of song is effective in learning English as songs open up many other possibilities as teaching resources, whether to acquire new structure and sentence patterns, learn vocabularies or even to learn the language culture, amounting to different aspects of and levels of intercultural communicative competence (ICC).

According to Kennedy and Torres-Santos (2016), the integration of music and written words could help expand and develop critical thinking skills in writing. They also found out from their study that music and written words can help produce and develop literacy skills and improve memorization of written words which is very useful for language learning. In another research, Salmon (2018) provides evidence that music serves as a medium to encourage thinking, express oneself, and increase cultural awareness in children. The study views music as a tool to promote children's cognitive skills as well as their literacy development. The findings of this study show that music can trigger children's schema and open up their imagination. Thus, music improves their comprehension and creative writing.

In another study, Lee \& Li (2016) state that melody serves as a path and a cue that triggers precise information where people try to retrieve but eventually leave a significant trace in memories. It means that the use of song increases the level of enthusiasm which helps learners to react strongly to the subject matter, thus leading to empowerment. Among the various studies on fluency, there is also a study specifically devoted to the development of 
written fluency. Alisaari and Heikkola (2016) have found out that singing songs have a greater impact on written fluency. Using three groups of students, they examined three different pedagogical methods - singing songs, listening to songs, and reciting lyrics of songs - and their impact on written fluency. Their study shows that the written fluency of the singing group has improved more than the other two groups - the reciting and listening groups.

\section{Research Objectives}

This study seeks to meet two objectives:

1. To enhance pupils' ability to write simple sentences using melodic sentence structure.

2. To identify pupils' perception in using melodic sentence structure to improve sentence writing.

3.

\section{Research Questions}

The study seeks to answer the following two questions:

1. How does the use of melodic sentence structure affect the pupils' writing of sentences?

2. What are the pupils' perceptions towards melodic sentence structure in learning to write sentences?

\section{Method}

\section{The Research Model}

This research is a mixed-methods approach that studies the effect of using melodic sentence structures on writing simple sentences. The research aims through the integration of simple melodies to introduce and help pupils internalize or grammaticalize certain sentence structures so as to enable them to write simple declarative sentences in various similar contexts - naturally and meaningfully.

\section{Participants}

The participants of this study were selected from a Year 5 class in a rural area school at Southern Perak that consists of 20 pupils. The samples for this study were selected nonrandomly from the population - convenient sampling. The data was collected from the participants who were conveniently available and easily reachable for the researchers. According to Stan (2012); Chostelidou \& Griva (2013), convenience sampling refers to nonprobability sampling that collects data from the population that is readily available to take part as a participant in a study. It is the quickest and easiest sampling where the researcher can select pupils from the current school to carry out the research and to collect the data.

\section{Data Collection Tool}

Qualitative and quantitative data collection methods were used in this study as it is a mixedmethods research. The data of this research was collected using two instruments to answer research questions one and two, respectively. The first instrument was used to answer research question one using a Pre-test and a Post-test. The Pre-test was carried out at the beginning of the research where the pupils were asked to write an essay based on a series of pictures. The question was adapted from the vernacular school UPSR 2018 paper (Appendix 1). The paper includes three sections but only one section was chosen to be focused on in this research - Section C. After the pre-test, MSS was implemented for four writing lessons. 
Pupils were introduced with the SVW sentence structure together with the MSS being followed by an exercise in the first lesson. The exercise given required the pupils to write at least three sentences using SVW sentence structure based on a picture. The second, third and fourth lessons were carried out by revising the SVW sentence structure, each followed by similar exercises with different pictures.

After the implementation of Melodic Sentence Structure (MSS), a post-test was conducted to identify the effectiveness of MSS. The question used in the post-test was in the same format as the one in the pre-test but with a different series of pictures being used. The post-test question was adapted from the vernacular school Pre UPSR 2019 paper (Appendix 2). Different series of pictures were used in the post-test to ensure that the pupils would write the essay with the help of MSS rather than by memorizing the answers.

The scoring of the test was based on the specifications of UPSR latest Marking Scheme (2016) where the pupils' writings would be graded in light of their accuracy and relevance of language used, task fulfillment and format. The tests were evaluated by an official UPSR Writing Paper marker with the specifications of UPSR Marking Scheme (Appendix 3). This was to ensure that the evaluation would be unbiased and the marks would be more reliable. The marks allocated for the essay of each test (pre-test and post-test) is 25 marks, divided into 5 bands, ranging from Extremely good to Weak Band as shown in Table 3.

\begin{tabular}{cc}
\hline Band & Marks \\
\hline Extremely good & $23-25$ \\
\hline Very good & $18-22$ \\
\hline Good & $12-17$ \\
\hline Satisfactory & $5-11$ \\
\hline Weak & $0-4$ \\
\hline
\end{tabular}

Table 3: Marks allocated for each band for UPSR Writing Paper

Besides that, an interview was used as an instrument to collect data to answer research question two. A semi-structured interview thus was conducted to collect qualitative data to find out about the pupils' perception of the use of melodic sentence structure on writing sentences. Five questions were asked for a few pupils on their perception and opinion about MSS (Appendix 4). Open-ended questions were developed and used during the interview to elicit information and to get in-depth responses from the pupils. The interview session was conducted in a controlled environment where the session was recorded and transcribed for further analysis.

\section{Analysis of Data}

The pre-test and post-test questions were collected, and the answers of the tests were then analyzed in the frequency on the number of pupils based on the ranging of bands. The mean and the standard deviation were calculated based on the scores obtained in the pre- and posttests. Finally, the data were presented in tables and graphs to allow readers to read and compare the findings of the research in order to see the significant difference between the pre-test and post-test. Data obtained from the interview were analyzed using thematic coding where the interview was recorded and transcribed. Important keywords were identified and categorized into several codes and categories. Themes were developed from the codes and categories derived from the interview transcription. The themes mainly highlighted the pupils' perception of the use of MSS on improving their sentence writing. 


\section{Findings}

Research Question 1: How does the use of melodic sentence structure affect the pupils' writing of sentences?

The marks obtained by the pupils in the pre-test and post-test are shown in Table 4.

\begin{tabular}{ccc}
\hline Pupil & Pre Test & Post Test \\
\hline A & 3 & 15 \\
\hline B & 3 & 17 \\
C & 2 & 23 \\
\hline D & 2 & 18 \\
E & 2 & 18 \\
\hline F & 3 & 17 \\
\hline G & 3 & 12 \\
\hline H & 2 & 14 \\
\hline I & 3 & 16 \\
\hline J & 2 & 15 \\
\hline K & 3 & 11 \\
\hline L & 6 & 16 \\
\hline N & 10 & 17 \\
\hline O & 8 & 15 \\
\hline P & 5 & 13 \\
\hline Q & 4 & 14 \\
\hline R & 11 & 18 \\
\hline S & 10 & 16 \\
\hline T & 9 & 17 \\
\hline & 12 & 18 \\
\hline
\end{tabular}

Table 4: Pre-test and Post-test marks

Based on the marks listed in Table 4, all of the pupils had an increase in their marks. The result of the post-test showed a great improvement whereby only one pupil obtained the highest score which is 23 out of 25 marks. The second highest mark is 18 which was obtained by 4 pupils and another 4 pupils with 17 marks.

\begin{tabular}{ccccccc}
\hline Test & Mean & Mode & Median & Range & Variance & Standard Deviation \\
\hline Pre-test & 5.15 & 3 & 3 & 10 & 12.13 & 3.48 \\
\hline Post-test & 16 & 17,18 & 16 & 12 & 6.5 & 2.55 \\
\hline
\end{tabular}

Table 5: The comparison of descriptive statistics in pre-test and post- test

From the table above, it can be seen that the mean score of the post-test is 16 which is significantly higher than the mean score of the pre-test which is only 5.15. The increase in the mean score shows positive improvement in the pupils' performance level; whereas the standard deviation of the post-test is 2.55 and it is lesser than the pre-test which is 3.48 . This shows that the dispersion of the marks is closer to the mean and it indicates that the pupils showed a positive result after the use of MSS to write sentences. 


\begin{tabular}{ccc}
\hline Bands & Pre-test & Post-test \\
\hline Extremely Good & 0 & 1 \\
\hline Very Good & 0 & 4 \\
\hline Good & 1 & 14 \\
\hline Satisfactory & 7 & 1 \\
\hline Weak & 12 & 0 \\
\hline
\end{tabular}

Table 6: The pupils' improvement according to bands

As can be seen in Table 6 above, the bands of pupils shifted significantly from weak to satisfactory (1 pupil); weak to good ( 8 pupils); weak to very good ( 2 pupils); weak to extremely good (1 pupil); satisfactory to good (6 pupils); satisfactory to very good (1 pupil) and good to very good (1 pupil). This proves the effectiveness of MSS when the pupils derived to a better band that showed the improvement of marks from pre-test to post-test.

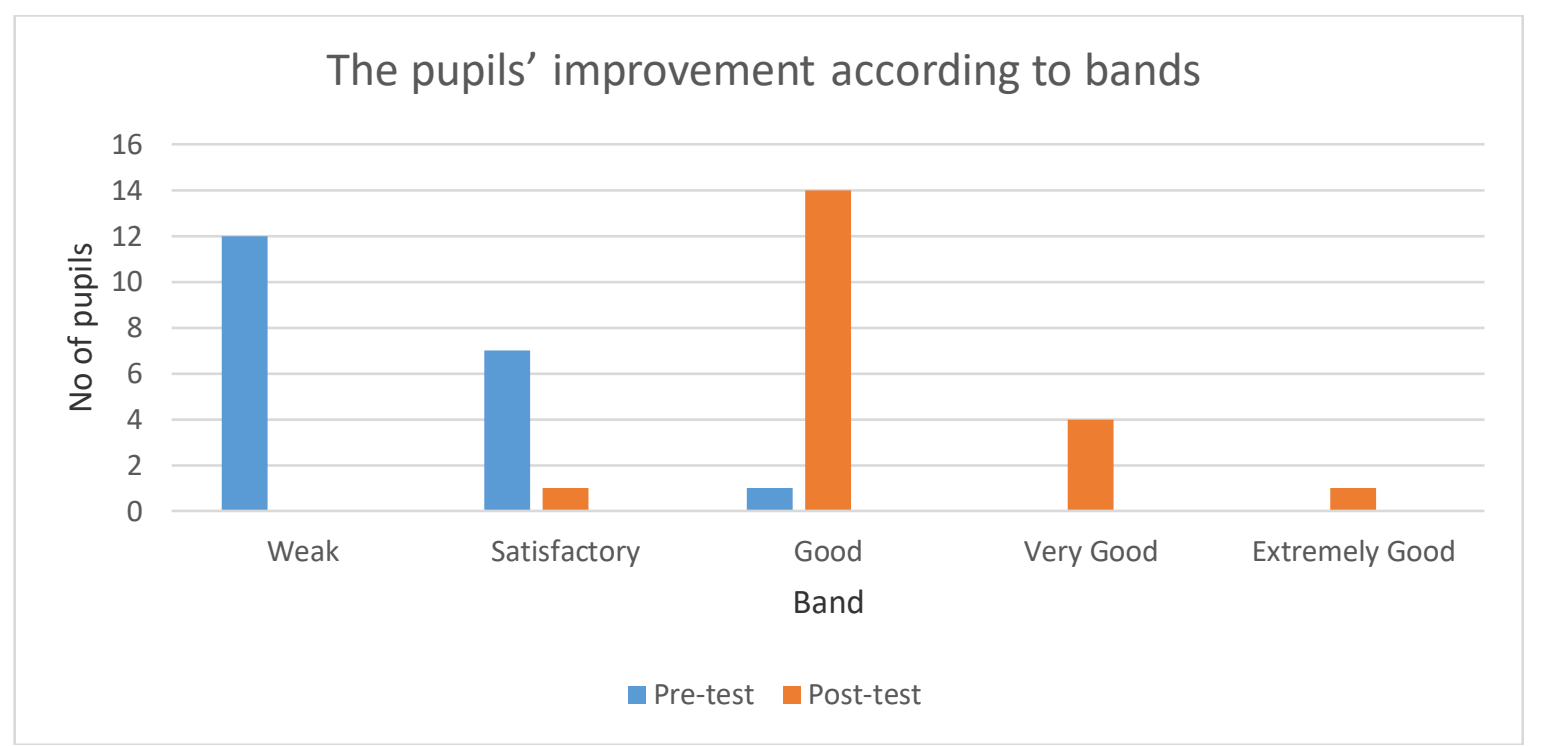

Figure 1: The pupils' improvement according to bands

According to Figure 1, the number of pupils in the weak band is the highest in the pre-test. This shows that the pupils obtained only 1 to 4 marks in the pre-test. This indicates that they had a very poor ability to make sentences with the correct structure. However, after the implementation of MSS, the pupils were able to improve to a higher band along with their improvement in marks respectively. More than half of the pupils managed to get a good band, i.e. somewhere between 12 and 17 marks in the post-test which is a tremendous increase compared to the pre-test. Furthermore, one of the pupils showed a remarkable improvement by obtaining 23 marks which is categorized in the highest band.

Research Question 2: What are the pupils' perceptions towards melodic sentence structures in learning to write sentences?

Based on the transcription of the interview (Appendix 5), several themes were derived from the interview data after coding the transcription. These themes are: easy to write sentences, better understanding of sentence structure, song that can be easily remembered, fun and entertaining as well as useful for examination and marks. These themes are proven to answer the second research question of this study. The table below indicates a summary of the 
themes and the codes derived from the interview transcription. The colour refers to the codes used to describe each response in the interview transcription (Appendix 5)

\begin{tabular}{|c|c|}
\hline $\begin{array}{l}\text { 1) Theme: MSS makes it easy to write } \\
\text { sentences } \\
\text { Codes:- } \\
\text { - Writing sentences becomes easy because } \\
\text { of MSS. } \\
\text { - Easy to write sentences } \\
\text { - Writing becomes better } \\
\text { - Easy method to write sentences properly }\end{array}$ & $\begin{array}{l}\text { 2) Theme: MSS gives a better } \\
\text { understanding of sentence structure } \\
\text { Codes:- } \\
\text { - The use of subject, past tense, what, } \\
\text { - } \text { where, who. } \\
\text { - Remember the sentence structure. } \\
\text { - } \quad \text { Hemember the flow of sentence. } \\
\text { - } \quad \text { Reminding about sentence structure. } \\
\text { - Understand and remember how to write } \\
\text { - } \quad \text { sentences. } \\
\text { - } \quad \text { Understand sentence structure better }\end{array}$ \\
\hline $\begin{array}{l}\text { 3) Theme: The song can be easily } \\
\text { remembered } \\
\text { Codes:- } \\
\text { - Catchy song } \\
\text { - Simple song } \\
\text { - Nice and easy song lyric } \\
\text { - Repetitive song lyric that is easy to } \\
\text { remember }\end{array}$ & $\begin{array}{l}\text { 4) Theme: MSS is very fun and } \\
\text { entertaining } \\
\text { Codes: - } \\
\text { - Learning using MSS is not boring. } \\
\text { - MSS produces a stress-free environment } \\
\text { - MSS is easy and fun } \\
\text { - Happy to write correct sentences } \\
\text { - Happy, fun and entertaining } \\
\text { - } \quad \text { Enjoyable to sing in class }\end{array}$ \\
\hline $\begin{array}{l}\text { 5) Theme: MSS is also useful for examina } \\
\text { Codes: - } \\
\text { - Happy to get good marks } \\
\text { - Can help to answer examination questions. }\end{array}$ & tion and marks \\
\hline
\end{tabular}

Table 7: Themes and the codes derived from the interview transcription

Theme one was obtained from the pupils' answer to interview question 1. All the pupils indicated that the process of writing sentences becomes easy with the use of MSS which shows that MSS aided them in writing better sentences. They also agreed that MSS helped them to write sentences easily and the codes are listed above. Some of the pupils compared their own writing before and after using the MSS method to write sentences.

Researcher: Do you think MSS helps you in writing sentences?

Pupil 1: "Before this, it was difficult to write sentences but now it became easier because of MSS."

Pupil 4: Before this, it was difficult to write sentences but now it became easier because of MSS.

This shows that the pupils are able to see their own improvement in sentence writing after making use of the MSS method. According to James (2013), using the song-shaped sentence structure would be a brilliant method to improve the writing skill. The second theme was obtained from the pupils' response for interview question 1, 2 and 5 . Throughout 
the interview, all the pupils stressed more about how MSS gave them a better understanding of sentence structure. They made it clear that the use of subject, past tense, what, where, who in melodic sentence structure enhanced their memory and reminded them about sentence structure every time they wrote a sentence.

Researcher: How does MSS help you in sentence writing?

Pupil 2: The use of subject, then past tense then what, where, who makes me to remember the flow of the sentences easily and it really helps me so much

Pupil 5: MSS remind me on what a sentence should have

James (2013) states that using this method, pupils can learn every single component of sentence structure separately and then integrate these separate components to form correct sentences. Besides that, the pupils also shared their perception about MSS in relation to the use of the song. This theme was derived from the responses given for interview question 2 and 3 . The simple and repetitive song attracted their attention and most of them said that the song is catchy and easy to remember.

Researcher: How does MSS help you in sentence writing?

Pupil 1: MSS song is very 'catchy' and I can easily remember it.

Researcher: What do you like the most about MSS?

Pupil 5: I can sing and remember the song and I like it because it is repetitive

This shows that the use of a short and simple song can be easily remembered and it has a positive influence on their memory retention which encourages them to use it when writing a sentence. According to Alisa and Nihada (2016), songs are an appropriate tool to promote meaningful learning experience among students and at the same time enhance their knowledge. The fourth theme was obtained from the responses of pupils for interview question 3, 4 and 5 . All the pupils gave many positive responses for the use of MSS as a strategy to improve their sentence writing. All of them said that they were happy in using it as MSS created a stress- free environment.

Researcher: What do you like the most about MSS?

Pupil 2: I like everything about MSS. It is because I feel not boring learning to write sentences using the song in MSS.

Researcher: How do you feel when you use it for sentence writing?

Pupil 3: I feel happy and fun to learn using MSS. I love to sing the song because it is entertaining. It's easy to remember and easy to write sentences too.

Pupil 4: I feel it is enjoyable because I can sing in the class to write sentences.

This shows that the use of MSS was able to shift the classroom, with the help of songs and music, from being traditional to one that is more fun and enjoyable. Shen (2009) claims that the use of adapted songs and music is always a better way to motivate students and avoid boredom as it creates a pleasant environment, particularly on the English teaching and learning process.

On the other hand, there are also some pupils who shared that MSS is very useful to answer examination questions and to get good marks. This theme is derived from the pupils' answer for interview question 4 and 5 . As stated earlier, the questions given to them as pretest and post-test were taken from UPSR and Pre UPSR questions. This shows that the pupils were able to relate the usefulness to their examinations and one of the pupils was very happy to get good marks for the post-test questions.

Researcher: How do you feel when you use it for sentence writing?

Pupil 5: Happy especially when my marks are better than before and now, I can write sentences correctly. 
The responses from the interview show that MSS played a vital role in helping the pupils to write simple sentences with correct sentence structure. Moreover, the pupils shared various positive perceptions of the use of MSS on enhancing their writing skill.

\section{Discussion, Conclusion and Suggestions}

The concern of this study was to explore the effectiveness of melodic sentence structure (MSS) on enhancing the ability to write sentences among Year 5 pupils. From the analysis of the data in this study, it has been revealed that there is a tremendous improvement in the marks of the pupils in the post-test compared to the pre-test. This shows that the implementation of MSS encourages the pupils to write sentences better, paving their way to eventually master sentence writing skills. Based on the themes and the analysis of the interview, it can be clearly seen that the pupils are having different and more positive perceptions of the use of MSS on learning to write sentences.

Pupils displayed their apparent liking towards the song that accompanies the sentence structure. They acknowledged that the song is interesting, fun, enjoyable, and most importantly significant in contributing to and grammaticalization of the sentence structure as well as helping them to write better sentences. The repetition of memorable rhythm in the song improved the pupils' memory retention of sentence structures as they were able to remember and understand the concept easily in a fun and an entertaining way. This is consistent with the findings of Atmojo (2015). This study has also proved that the proposed remedy - using melodic sentence structures - enables and helps the pupils to overcome their weakness as well as their low confidence level in writing sentences to form paragraphs. One fundamental contribution made by using melodic sentence structure in the teaching of sentence writing was the ability to familiarize and give pupils a clearer view of how to write sentences with the correct structure. This is in line with the findings of James (2013).

However, the implementation of melodic sentence structure in this research can be improved to make further research. It is recommended to carry out this research and to implement melodic sentence structure at an early stage of schooling. It would be beneficial for lower primary pupils especially Year 3 pupils who are still new to sentence writing. It is important to build a strong foundation in mastering writing skills to become good writers in the future. The lower primary pupils can be exposed to simple sentences using any songs or rhythm that suits the pupils and their context. Moreover, in this study, MSS was used specifically to teach simple sentences. Hence, MSS should be used to explore other sentence types and encourage the pupils to write other tenses too.

\section{Corresponding Author (Dr Mahendran Maniam)}

Mahendran Maniam, obtained his Diploma in Teaching (TESL) from Penang Teachers' Training College Malaysia in 1989, Bac. Ed. (TESL) Hons. from Putra University Malaysia in 2001, M.Ed. (TESL) Malaya University, Malaysia in 2004 and Ph. D. (TESL) from International Islamic University of Malaysia in 2009. Formerly English Language teacher, he taught in government and independent schools in many parts of Malaysia. He is currently attached to Sultan Idris Education University, Malaysia in the faculty of Languages and Communication as an Associate Professor. His research areas are mainly in Applied Linguistics. He has done extensive research in the field of mother tongue interference, Second Language Acquisition and language learning strategies. He currently conducts research and supervises doctoral and master students in a range of Second Language Acquisition and Language Learning Strategies. 


\section{References}

Alisa, P., \& Nihada, D, D. (2016). The effect of using songs on young leaners and their motivation for learning English. New Trends in Social and Liberal Science, 1(2), 40-54.

Alisaari, J., \& Heikkola, L. M. (2016). Increasing fluency in L2 writing with singing. Studies in Second Language Learning and Teaching, 6(2), 271-292.

Atmojo, A. E. (2015). Utilizing song "There is an Animal" to teach vocabulary and basic sentence structure to young learners through three stages activity. Language Education in Asia, 2(3), 1-12.

Chostelidou, D., \& Griva, E. (2013). In-service Training Needs of English Language Teachers and Vocational Education. Multilingual Academic Journal of Education and Social Sciences, 1(1), 1-18.

Engh, D. (2013). Use music in English language learning? A survey of the Literature. English Language Teaching, 6(2), 113-128.

Iftanti, E. (2016). Improving student's writing skill through journal writing articles. Lingua Scientia, 8(1), 1-22.

James, C. C. (2013). Pre-writing module 1: Developing basic sentence construction skill among weaker upper-primary pupils. Paper presented at 22nd MELTA Conference, Johor Bharu, Malaysia. Retrieved from https://www.academia.edu/9052194/PreWriting_Module_1_Developing_Basic_Sentence_Construction_Skill_Among_Weaker _Upper_Primary_Pupils

Kennedy, E. P., \& Torres-Santos, R. (2016). Music and words: Connection the love of music with language. City University of New York Academic Works, 2(3), 131-146.

Klimnova, B. F. (2014). Approaches to the teaching of writing skills. Social and Behavioral Sciences, 112 (12), $147-151$.

Lee, L., \& Li, T. Y. (2016). The impact of music activities in a multi-sensory room for children with multiple disabilities on developing positive emotions: a case study. Journal of the European Teacher Education Network, 11(1), 1-12.

Millington, N. T. (2011). Using songs effectively to teach English to young learners. Language Education in Asia, 2(1), 134-141.

Salmon, A. (2018). Using music to promote children's thinking and enhance their literacy development. Early Child Development and Care, 1(1), 1-8.

Sapkota, A. (2012). Developing students' writing skill through peer and teacher correction: an action research. Nepal English Language Teachers' Association, 17(2), 70-82.

Shen, C. (2009). Using English songs: An enjoyable and effective approach to ELT. English Language Teaching, 2(1), 88-94.

Stan, R. (2012). Convenience Sampling. Retrieved from http://researchmethodology.net/sampling-in-primary-data collection/convenience-sampling/

Supiani. (2017). Teaching writing skill through collaborative writing technique: from theory to practice. Journal of English Education and Linguistics Studies, 4(1), 37-52. 